\title{
Inflammatory breast cancer
}

\author{
Andrew Hague* \\ Professor of Advanced Medicine, President, Cellsonic, Manufacturers of Medical Equipment, UK
}

\section{Introduction}

Thought you'd like to see the attached report. Inflammatory breasts are terrible. Just one CellSonic completely relieved the breast cancer pain. She has already gone back to (country not to be disclosed) She may be back down here in a month. Funds are tight for her. Will approach her for some words if she's back.

\section{Case report}

\section{Inflammatory Breast Cancer: Stage 4}

Before the first therapy session, the patient was asked about her pain level on a one to ten scale, she reports that she was at a 14! She is obviously unbearably uncomfortable with constant groaning and fidgeting. Inflammatory breast cancer is mainly in her right breast and some in the left breast and also her spine. She then has one therapy session.

Three weeks later, she returns for another therapy session. When asked about her pain level, she says she "has no pain, just some discomfort in the tops of both breasts". There is, however, pain in her upper neck which may be from a pathological fracture. There will be $\mathrm{x}$-rays taken of her neck to diagnose what is happening (Figure 1).

\section{Result}

You may have already stopped the cancer and what remains could be for a plastic surgeon. However, give her another two or three treatments and check if the skin lesions show signs of healing. I think you have gone from cancer to wound healing. This is a good case because it is visual. Is the lady able to say a few words into a video recorder?

I think when you can see the enormity of cancer, you realise how devastating it is. Then in a few minutes, a machine can stop it. What

Copyright: (C2019 Hague A. This is an open-access article distributed under the terms of the Creative Commons Attribution License, which permits unrestricted use, distribution, and reproduction in any medium, provided the original author and source are credited.

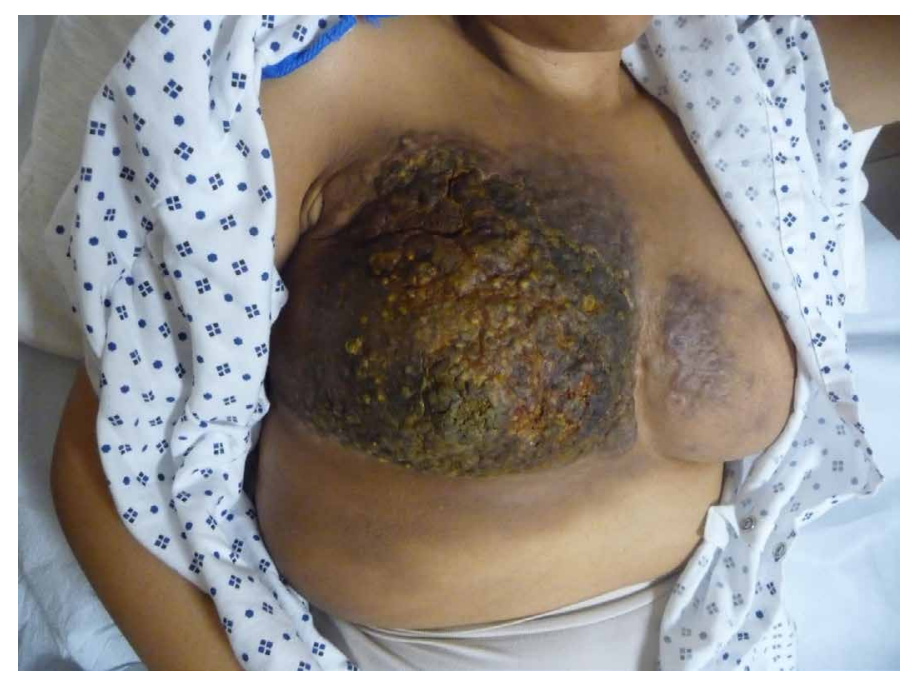

Figure 1. Lady with breast cancer

will the pharma companies say? If only she had been treated very much earlier. This proves what CellSonic can do and what other methods cannot do.

\section{Conclusion}

That her cancer stopped is plausible. The replication of mutating cells is known to be stopped immediately when aimed at by CellSonic. The polarity of the cells is changed by the electro-magnetic field.

The benign tumors and skin lesions do not immediately disappear. CellSonic has many years of success healing non-healing diabetic ulcers so continued treatment by CellSonic is advised with the proviso that the tumors be observed because, although now benign, they do not have chalones.
*Correspondence to: Andrew Hague, Professor of Advanced Medicine, President, Cellsonic, Manufacturers of Medical Equipment, UK, Tel: +1 315210 6307; E-mail: cellsonic.beauty@gmail.com

Received: January 03, 2019; Accepted: January 14, 2019; Published: January 16, 2019 